\title{
Nanofibers Pure And Doped With a Transition Metal: $\mathrm{BaTiO}_{3}$ and $\mathrm{LiNbO}_{3}$
}

M.C. Maldonado-Orozco ${ }^{1}$, R. Narro-García ${ }^{1}$, C. Nava-Dino ${ }^{1}$, J.P Flores-De los Ríos ${ }^{1}$, M.T. OchoaLara $^{2}$ and F. Espinosa-Magaña ${ }^{2}$.

${ }^{1 .}$ Facultad de Ingeniería de la Universidad Autónoma de Chihuahua, Nuevo Campus s/n, Chihuahua, México.

2. Centro de Investigación de Materiales Avanzados, S.C., Laboratorio Nacional de Nanotecnología, Chihuahua, México.

Nowadays one dimensional nanomaterials such as nanofibers, have been synthesized by various processes, e.g. solution method, sol-gel, laser ablation, chemical vapor deposition (CVD), hydrothermal method and mechanochemical activation. In this work, structures $\mathrm{ABO}_{3}$ such as $\mathrm{BaTiO}_{3}$ and $\mathrm{LiNbO}_{3}$ nanofibers were doped with Mn like transition metal and synthesized by electrospinning method, a detailed description of the procedure can be found in the literature [1][2]; this technique has been recognized as an efficient method to make polymeric nanofibers [3], who it is a straightforward way to synthesize nanostructures.

The potentials applications of these materials are focused in one of the extensively studied ferroelectric material with wide range of applications in non-volatile ferroelectric random access memories, as transducers, sensors and actuators, etc [4].

The presence of a pure phase and patterns from $\mathrm{BaTiO}_{3}$ doped is confirmed by XRD analysis, Fig 1 . In the other hand, the presence of a pure phase and patterns from $\mathrm{LiNbO}_{3}$ doped is confirmed in Fig 2. The metal transition is used to dope the composite taking care the $\mathrm{BaTiO}_{3}$ and $\mathrm{LiNbO}_{3}$ stoichiometry. Such as Fig 1. and Fig 2. show the "x" value, that in both cases corresponds to 2.5, 5 and $10 \%$. In $\mathrm{BaTiO}_{3}$ doped to the $10 \%$ change it from tetragonal to hexagonal structure.

Fig 3. and Fig 4. show a SEM micrograph of as-spun fibers, $\mathrm{BaTiO}_{3}$ and $\mathrm{LiNbO}_{3}$ respectively. Cylindrical and randomly oriented $\mathrm{BaTiO}_{3}$ fibers with diameter about 57-453 nm were obtained, compared with diameter about 57-146 nm obtained by $\mathrm{LiNbO}_{3}$.

TEM micrographs, Fig 5. and Fig 6, show a isolated and calcined $\mathrm{BaTi}_{0.95} \mathrm{Mn}_{0.05} \mathrm{O}_{3}$ and $\mathrm{LiNb}_{0.95} \mathrm{Mn}_{0.05} \mathrm{O}_{3}$ nanofibers respectively, both in the same $\mathrm{Mn}$ concentration. In Fig 5 , it can be observed fibers with few $\mu \mathrm{m}$ in length and an irregular morphology. Fig. 6 shows TEM micrograph, different surface morphology is evident.

References:

[1] J. Yuh, J.C. Nino and W.M. Sigmund, Materials Letters 59 (2005) p. 3645.

[2] M.C. Maldonado-Orozco et al, Ceramics International 41 (2015) p. 14886.

[3] J. P. Chu et al, J. Mater. Sci. 42 (2007) p. 346.

[4] S. Sharma, Adv. Mater. Lett. 4 (2013) p. 522. 


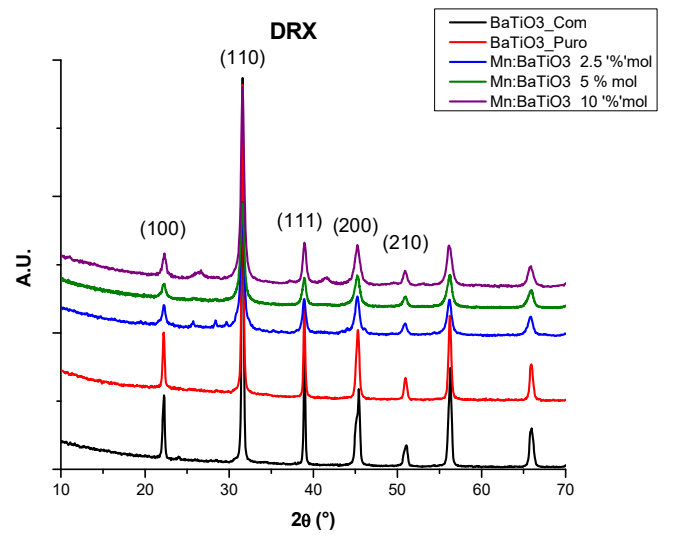

Figure 1. $\mathrm{XRD}$ pattern $\mathrm{BaTi}_{1-\mathrm{x}} \mathrm{Mn}_{\mathrm{x}} \mathrm{O}_{3}$

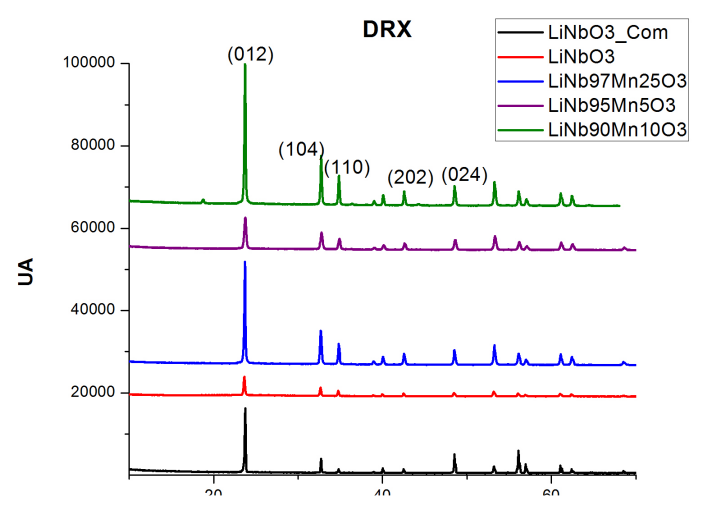

Figure 2. XRD pattern $\mathrm{LiNb}_{1-\mathrm{x}} \mathrm{Mn}_{\mathrm{x}} \mathrm{O}_{3}$

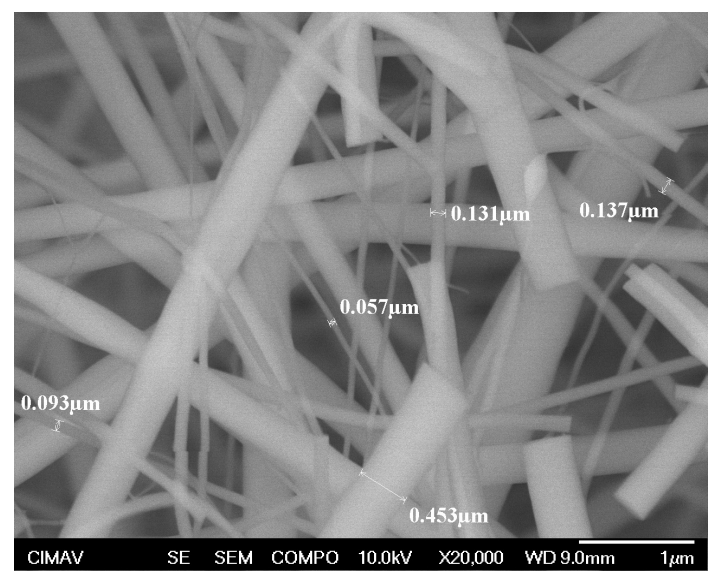

Figure 3. SEM images of as-spun $\mathrm{Ba}\left(\mathrm{C}_{2} \mathrm{H}_{3} \mathrm{O}_{2}\right)_{2}: \mathrm{Ti}\left[\mathrm{OCH}\left(\mathrm{CH}_{3}\right)_{2}\right]_{4}: \mathrm{PVP}: \mathrm{CH}_{3} \mathrm{CO}$ $\mathrm{OH}: \mathrm{H}_{2} \mathrm{O}: \mathrm{C}_{2} \mathrm{H}_{5} \mathrm{OH}$ composite.

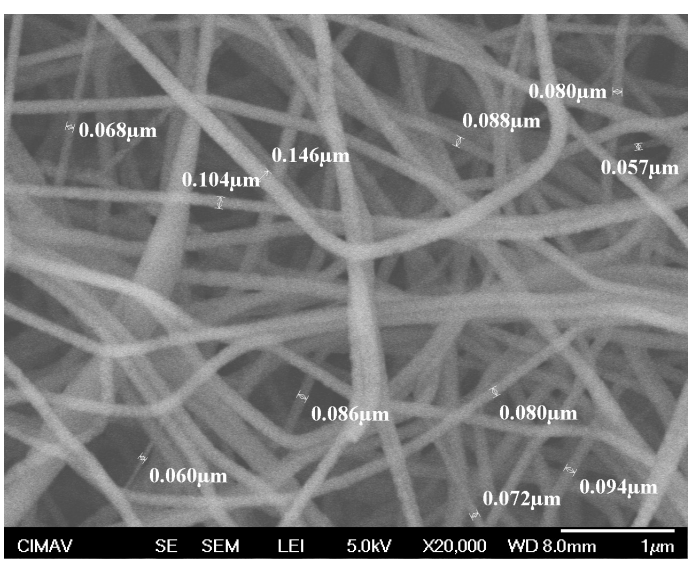

Figure 4. SEM images of as-spun HLiO: $\mathrm{Nb}\left(\mathrm{OCH}_{2} \mathrm{CH}_{3}\right)_{5}: \mathrm{PVP}: \mathrm{CH}_{3} \mathrm{COOH}$ : $\mathrm{C}_{2} \mathrm{H}_{5} \mathrm{OH}$. composite.

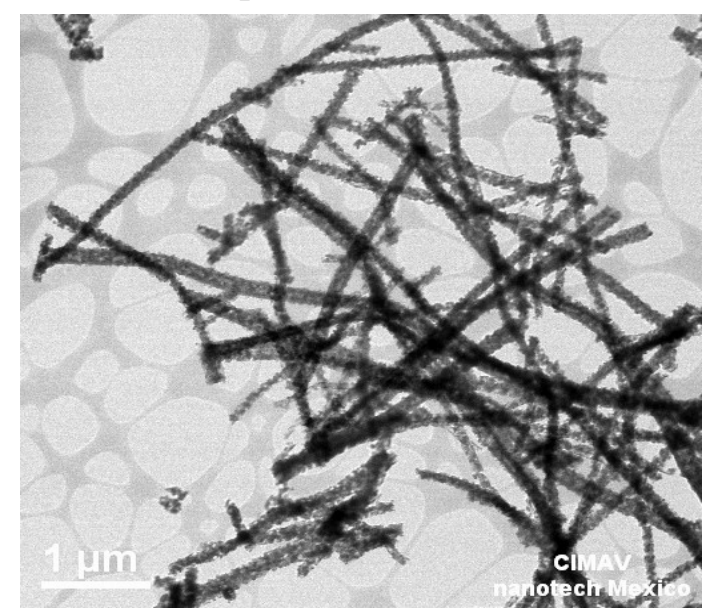

Figure 5. TEM image of $\mathrm{BaTi}_{0.95} \mathrm{Mn}_{0.05} \mathrm{O}_{3}$ nanofibers.

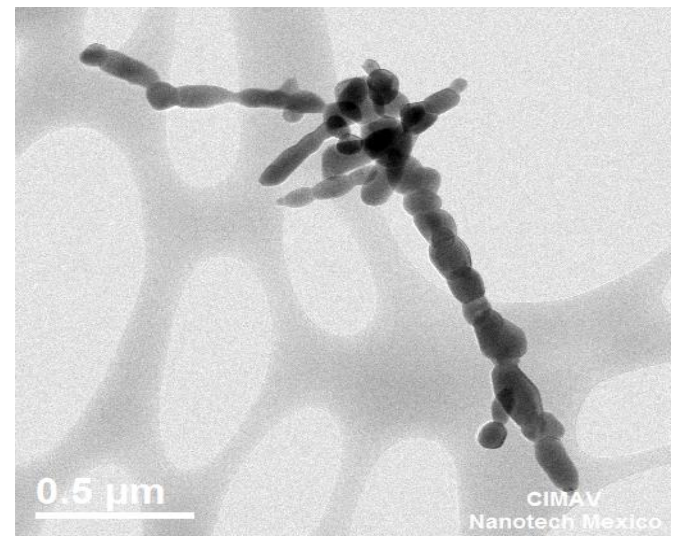

Figure 6. TEM image of $\mathrm{LiNb}_{0.95} \mathrm{Mn}_{0.05} \mathrm{O}_{3}$ nanofibers. 